\title{
Tuberculous Pseudoaneurysm of Descending Abdominal Aorta in Association with Tuberculosis of Spine: A Rare Complication
} Tongning Wang*, Nan Zhang, Jiayi Liu, Yu Li and Zhanming Fan

Department of Radiology, Capital Medical University Affiliated Anzhen Hospital, Anzhenli, Chaoyang District, Beijing 100029, P.R.China

\begin{abstract}
Tuberculous pseudoaneurysm of aorta is an unusual entity, with fewer than 20 cases reported in the English-and Chinese-language literature, only 2 reports are related to $M$. tuberculosis infection of spine. We describe another case of tuberculous pseudoaneurysm of aorta in association with tuberculosis of spine.
\end{abstract}

Keywords: Tuberculous pseudoaneurysm; Aorta; M. tuberculosis; Spine

\section{Case Report}

A 20-year-old man with dull osphyalgia and intermittent hemoptysis for 8 months came to emergency department of our hospital due to sharp pain of back without the history of trauma [1-15]. At the time of admission, his vital signs were stable without fever (36.5 $\left.{ }^{\circ} \mathrm{C}\right)$. The findings of the physical examination were negative. Laboratory studies revealed positive finding of PPD test. Sputum staining and culture for acid-fast bacilli were positive. The patient was treated with anti-tuberculosis drugs for 7 days and went home without treatment of pseudoaneurysm since the infection of $M$. tuberculosis is in active stage.

A 20-year-old man with Tuberculous pseudoaneurysm of aorta in association with tuberculosis of spine (Figures 1A-1D).

\section{Discussion}

A pseudoaneurysm is a hematoma that forms as the result of a leaking hole in an artery. The formation of a pseudoaneurysm begins with a defect in the arterial wall. Blood then leaks through the defect into the extravascular space where it is encapsulated by connective tissue and becomes organized. Pseudoaneurysm secondary to infection of $M$. tuberculosis is a rare complication. It was first reported by Weigert in 1882 [3] Till now, less than 100 cases were reported all around the world. Among all case reports collected by the writer of article, only 2 case reports $[7,8]$ were found in relationship with tuberculosis of spine, others were caused by miliary tuberculosis of lung and other kinds of reasons. In our patient, the pseudoaneurysm arose from the erosion of a tuberculous vertebra into the abdominal

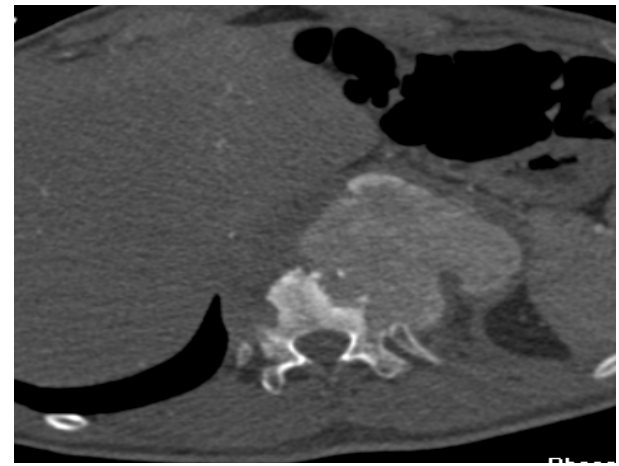

Figure 1A: Axial abdominal CTA shows a $8.6 \times 4.5 \mathrm{~cm}$ out-pouching pseudoaneurysm of the proximal descending abdominal aorta.

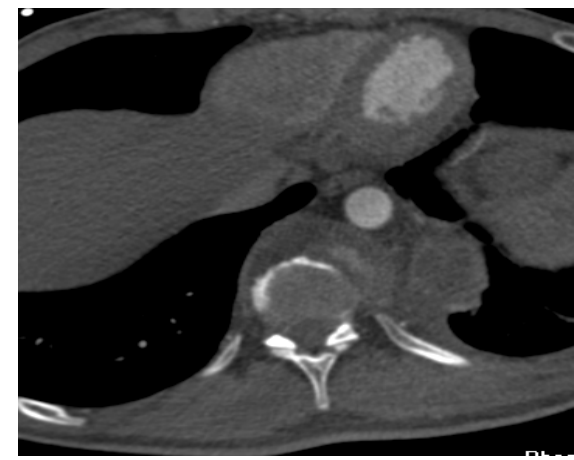

Figure 1B: Axial abdominal CTA shows bulge of left psoas major muscle into ipsilateral chest, leading to compression of left lung tissue.

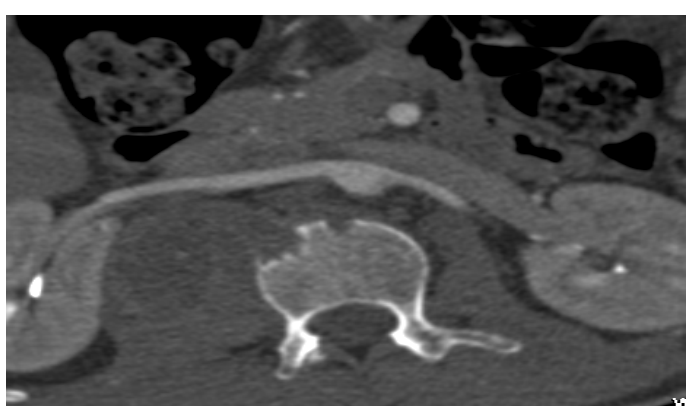

Figure 1C: Axial abdominal CTA shows irregular contrast enhancement of right psoas major muscle.

aorta. The pathogenesis observed in our patient arose from a nearby focus of inflammation eroding through the vessel wall. Recognition of tuberculous pseudoaneurysms remains difficult because they are

*Corresponding author: Tongning Wang, Capital Medical University Affiliated Anzhen Hospital Beijing, Beijing, China, Tel: +8613810023121; E-mail: 1146696686@qq.com

Received June 27, 2016; Accepted August 04, 2016; Published August 10, 2016

Citation: Wang T, Zhang N, Liu J, Li Y, Fan Z (2016) Tuberculous Pseudoaneurysm of Descending Abdominal Aorta in Association with Tuberculosis of Spine: A Rare Complication. J Vasc Med Surg 4: 279. doi: 10.4172/2329-6925.1000279

Copyright: ( 2016 Wang T, et al. This is an open-access article distributed under the terms of the Creative Commons Attribution License, which permits unrestricted use, distribution, and reproduction in any medium, provided the original author and source are credited. 
Citation: Wang T, Zhang N, Liu J, Li Y, Fan Z (2016) Tuberculous Pseudoaneurysm of Descending Abdominal Aorta in Association with Tuberculosis of Spine: A Rare Complication. J Vasc Med Surg 4: 279. doi: 10.4172/2329-6925.1000279

Page 2 of 2

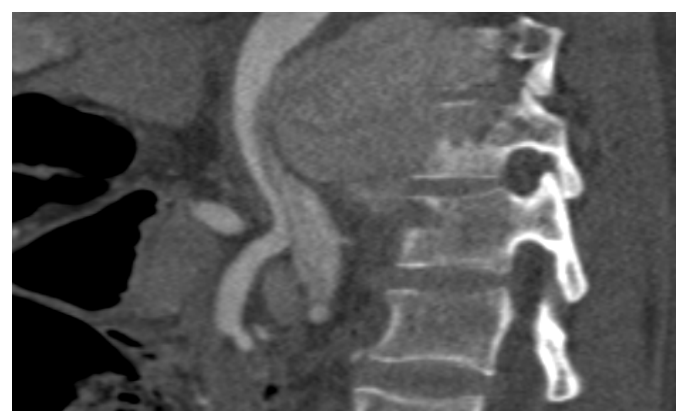

Figure 1D: Axial abdominal CTA shows bone destruction of L9-L12 vertebra.

so rare. They may present as a palpable mass in the superior of skin. Patients may also complain pain at the site of the aneurysm which may be accompanied by fever. Rupture or perforation of the aneurysm may lead to lethal lesion such as hemodynamic shock.

\section{Conclusion}

In summary, we report a case of a 20 -year-old male with tuberculous vertebra with pseudoaneurysm formation of descending aorta. Pseudoaneurysm is a rare complication of infection of M. tuberculosis. It is recommended that contrast-enhanced CTA is the most proper choice. Treatment should include a full course of antituberculous chemotherapy and vascular surgery. If unrecognized, they may rupture with possibly lethal consequences.

\section{References}

1. Syed S, Shahid AS (2013) Tuberculous ascending aortic pseudoaneurysm. Interact Cardiovasc Thorac Surg 17: 742-743.

2. Dong JS, Joon BK (2012) Tuberculous Aortitis Complicated with Pseudoaneurysm Formation in the Descending Thoracic Aorta: A Case Report. Korean J Thorac Cardiovasc Surg 45: 408-411.
3. Alae M, Brahim L, Abbes M, Fannid A, Younes B (2011) Ruptured Tuberculous False Aneurysm of the Abdominal Aorta: A Case Report. Ann Vasc Dis 4: 4749.

4. Loureiro R, Bezerra HG, Sarwar A, Pale R, Houser S, et al. (2009) Comprehensive Evaluation by Cardiovascular Magnetic Resonance Images in Cardiovascular Magnetic Resonance. Circulation.

5. Amonkar GP, Vaideeswar P, Metkar GS (2009) Oesophageal rupture due to tuberculous pseudoaneurysm of the aorta. J Clin Pathol.

6. Han JT, Zhao J, Luan J, Zhang L (2007) Multiple tuberculous abdominal aortic aneurysm. Journal Of Peking University (Health Sciences).

7. Jain AK, Chauhan RS, Dhammi IK, Maheshwari AV, Ray R (2007) Tubercular pseudoaneurysm of aorta:a rare association with vertebral tuberculosis. The Spine Journal 7: 249-253.

8. Sirvanci M, Onat L, Karaman K, Yagan N, Sonmez B (2006) Recurrent Tuberculous Pseudoaneurysm of the Descending Thoracic Aorta A Case Report. Angiology 57: 103-106.

9. Aebert H, Birnbaum DE (2003) Tuberculous pseudoaneurysms of the aortic arch. J Thorac Cardiovasc Surg 125: 411-412.

10. Choudhary SK, Bhan A, Talwar S, Goyal M, Sharma S, et al. (2001) Tubercular Pseudoaneurysms of Aorta. Ann Thorac Surg 72: 1239-1244

11. J Golzarian, J Cheng, F Giron, TV (1999) Bilfinger Tuberculous pseudoaneurysm of the descending thoracic aorta: successful treatment by surgical excision and primary repair. Tex Heart Inst J 26: 232-235.

12. Ikezawa T, Iwatsuka Y, Naiki K, Asano M, Ikeda S, et al. (1996) Tuberculous pseudoaneurysm of descending thoracic aorta: A case report and literature review of surgically treated cases. J Vasc Surg 24: 693-697.

13. Colucci V, Moreo A, Passini L, Gordini V, Fedriga E, et al. (1992) Successfu Resection of a Tuberculous Pseudoaneurysm of the Descending Thoracic Aorta Case Report and Review of the Literature. Tex Heart Inst J 19: 142-145.

14. Peyton RW (1965) Surgical correction of tuberculosis pseudoaneurysm of upper abdominal aorta: First Reported Case. Annals of Surgery 162: 10691074.

15. Ming W, Jianrong $X$, Yong L, Occasion TF, Xifeng $H$ (2009) Tuberculous aortic aneurysm case report and literature review. Chin J Postgrad Med. 